\title{
A Critical Study of English Eco-hotel Profiles- Based on Fairclough's Three-dimensional Model
}

\author{
Juan Qiu \\ School of Foreign Languages, Wuhan Polytechnic University, Wuhan, China
}

\begin{abstract}
Eco-hotels are promoted to minimize the negative impacts on the environment. The author, therefore, makes a critical study of English eco-hotel profiles in order to decode the ecological thoughts embodied in the profiles. Based on Fairclough's three-dimensional model, this study follows the three steps: description of linguistic features in terms of transitivity, interpretation of ecological thoughts, and explanation of social reasons. After examining transitivity in twenty English eco-hotel profiles, the author finds that material processes and relational processes enjoy the overwhelming occurrence. They serve to construe the ecological thought that we human beings should identify ourselves with nature and minimize our impacts on nature. In a society in which mankind has gradually been alienated from nature, the eco-hotel founders, as profit-seeking businessmen, tend to convey ecological thoughts in their profiles since such endeavor can earn them both fame and fortune. Seen from the study, the linguistic resources used in English eco-hotel profiles convey the prevailing ecological thoughts, which may influence readers' ecological ideologies and lifestyles. Correspondingly, readers are supposed to have a critical look at the language use that expresses ecological or un-ecological thoughts.
\end{abstract}

Index Terms-English eco-hotel profiles, Fairclough's three-dimensional model, ecological thoughts, transitivity

\section{INTRODUCTION}

Along with deteriorating natural environment and mounting ecological crises, eco-tourism, a new type of tourism has arisen, which includes programs that minimize negative aspects of conventional tourism on environment, contribute to the sustainability of tourist resources and enhance the cultural integrity of local people. With the development of eco-tourism, eco-hotels have emerged. According to Wikipedia, eco-hotel is a term used to describe a hotel or accommodation that has made important environmental improvements to its structure in order to minimize its impact on the environment. An eco-hotel must usually meet the criteria as follows, dependence on the natural environment, ecological sustainability, proven contribution to conservation, provision of environmental training programs, incorporation of cultural considerations, and provision of an economic return to the local community (Http://en.wikipedia.org/wiki/Eco-hotel). The founders of eco-hotels not only try hard to provide guests with comfortable and environment-friendly accommodation, but also wish to present and equip their guests with ecological consciousness. And the hotel profile is undoubtedly a desirable channel for them to display and promote their ecological awareness and environmental concern.

Thus, how can they express their ecological thoughts? What kinds of linguistic resources do they apply in the profiles? What kind of social contexts drive them to make such endeavors? These questions motivate the author to conduct the current study, which is committed to the exploration of the ecological thoughts conveyed in English eco-hotel profiles, thus shedding lights on the interrelationship among language, environment and society. The author has selected randomly twenty English eco-hotel profiles from the website Eco-Hotels of the World, and made a statistical analysis of the linguistic resources in terms of transitivity in all the profiles. And one profile is chosen for case study, which, based on Fairclough's three-dimensional model, first describes the linguistic features in the profile, then interprets the involved ecological thoughts, and consequently makes an explanation of the social reasons.

\section{THEORETICAL FRAMEWORK}

\section{A. Fairclough's Three-dimensional Model}

Fairclough (1989 \& 1992) puts forward three stages of discourse analysis, be they description, interpretation and explanation respectively. Description, concerned with the analysis of text, is the linguistic description of the language text in terms of linguistic devices and concepts mainly by making use of Systemic Function Grammar. Interpretation, concerned with the analysis of discourse practice, is interpretation of the relationship between the productive and interpretative discursive processes and the text, with attention paid to the situational contexts in which text production, distribution and consumption occur. Explanation, concerned with the analysis of social practice, is explanation of the relationship between the discursive processes and the social processes, in other words, it aims to analyze the discourse within a wider social practice or identify the social determination and social effects of the discourse, as Fairclough (1989) believes that explanation of social practice involves analysis whose "objective... is to portray a discourse as part 
of a social process, as a social practice, showing how it is determined by social structures, and what reproductive effects discourses can commutatively have on those structures, sustaining them or changing them" (p.163).

The three-dimensional concept of discourse and the corresponding analytical methods constitute the three-dimensional model of Fairclough, as shown in Figure 1.

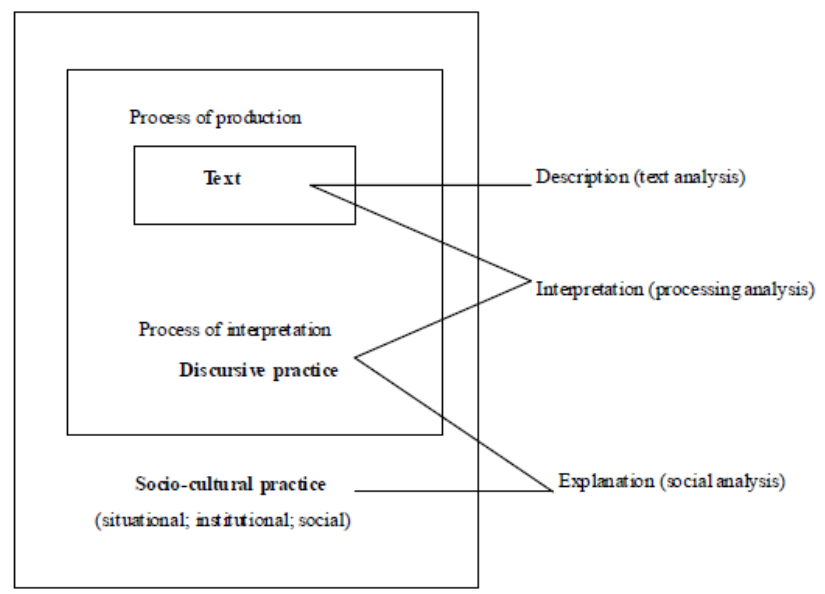

Figure1 Fairclough's Three-Dimensional Model

Just as the three dimensions of discourse are interrelated with each other, these three stages of discourse analysis also enjoy close interconnection, which is shown in the fact that the analysis of discursive practice serves as a bridge between text and social practice analysis. According to Fairclough (1992), a special feature of this three-dimensional approach to discourse analysis is that "the link between socio-cultural practice and text is mediated by discursive practice" (p.9). Fairclough (1995) values the feature as one of the significant principles of CDA, that is, analysis of text should not be artificially isolated from analysis of institutional and discursive practices within which texts are embedded.

Seen from the above discussion, it can be concluded that the analysis of any specific discourse requires all the three interrelated stages, which cannot be separated from one another. The point can be well justified by Fairclough's (1992) comments on the interrelationship between description and interpretation, "description is not as separate from interpretation as it is often assumed to be. As an analyst and as an ordinary text interpreter, one is inevitably interpreting all the time, and there is no phase of analysis which is pure description" (p.199).

\section{B. Transitivity}

Halliday (1994) believes that "the transitivity system construes the world of experience into a manageable set of process types" (p.106) and puts forward six types of processes: material, relational, mental, verbal, behavioral and existential, among which, material, relational and mental processes being the major types.

Material processes are processes of "doing". They express the notion that some entity "does" something-which may be "done to" some other entity and represent something that goes on in the external world (Halliday, 1994, p.103). In this process, there is at least one participant acting as the "doer", which is called "actor"; if there is another participant who suffers or undergoes the process or at whom the action is directed, it is termed as "goal" (Huang Guowen, 2001, p.86).

Relational processes are processes of "being". In relational clauses, something is described in terms of something else. In other words, a relation is being set up between two separate entities (Halliday, 1994, p.119). There are two modes of relational processes: the attributive mode and the identifying mode. In the attributive mode, an entity is endowed with particular quality, with the entity referred to as "carrier" and the quality as "attribute". (Halliday, 1994, p.115). In the identifying mode, an entity is being used to identify another one, with the entity used to identifying others being "identifier" and the entity to be identified being "identified". (Halliday, 1994, p.116). The attributive mode emphasizes the quality, property and contents of an entity, demonstrated by its efforts to express what attribute a certain object has, or what type it belongs to; the identifying mode focuses on the identity of a particular entity and expresses the identical properties of entities (Halliday, 1994, p.114). In a word, relational processes are used to describe things in terms of their qualities, attributes or identities.

Mental processes are processes of "sensing" (Halliday, 1994, p.112). While material processes represent things or events going on in the external world, mental processes depict the pictures of what is going on in the inner world. Participants involved in the process are senser and phenomenon. The Senser is "the conscious being that is feeling, thinking or seeing" and the phenomenon is hence "that which is "sensed'-felt, thought or seen" (Halliday, 1994, p.114).

Verbal processes are processes of "saying". Halliday points out that "saying" has to be interpreted in a rather broad sense; it covers any kind of symbolic exchange of meaning, like "the notice tells you to keep quiet", or "my watch says 
it is half past ten". The grammatical function of "the notice", "my watch" is that of "sayer" that is not necessarily a human being, but can be anything related with symbolic exchange of meaning. (Halliday, 1985, p.115).

Behavioral processes are processes of (typically human) physiological and psychological behavior, like breathing, coughing, smiling, sighing, dreaming and staring (Halliday, 1985, p.114). Typically, behavioral processes have only one participant: the human behaver, the person who is "behaving" that is also conscious being like the senser in mental processes, but grammatically it sounds more like material processes. (Thompson, 1996, p.99).

Existential processes represent something that exists or happens. There is only one participant involved, termed as "existent" that may be an event, an object or a human being (Halliday, 1985, p.115).

By virtue of the above discussion, it is understood that speakers or writers express their world views or experiences of the external as well as inner world by choosing one particular process type instead of other processes, or by placing participants in specific positions, which betrays speakers' or writers' viewpoints towards the world or reality.

\section{Analytical Framework of the Study}

To decode the ecological thoughts in English eco-hotel profiles and reveal the interaction among language, environment and society, the author employs Fairclough's three-dimensional model as the analytical framework of the study.

In practice, the first two steps-description and interpretation are combined to explicitly present the ecological thoughts. The linguistic features in the English profile texts are described, and then the ecological thoughts conveyed by these linguistic devices are interpreted. Regarding the linguistic features, transitivity will be analyzed in terms of processes and participants. By analyzing transitivity in eco-hotel profile texts, a general idea will be obtained of the profile writer's knowledge of and viewpoint towards eco-hotels, e.g. which aspect of eco-hotels the writer pays most attention to. After exposing the ecological thoughts through description and interpretation, we will try to explain the social reasons, that is, under what kind of social contexts are such thoughts derived and in turn, how such thoughts influence the language use.

In summary, we first describe the linguistic features of English profile texts in terms of transitivity, and then interpret the ecological thoughts reflected by the linguistic devices; and finally we try to explain the discursive practice from a socio-cultural perspective.

\section{DATAANALYSIS}

\section{A. The Statistical Analysis of the Data}

Before analyzing the sample profile, the author makes a statistical study concerning the distribution of the transitivity processes in all the profile texts. First, the transitivity processes in all profile texts are classified and counted so as to know the distribution in general. After that, one sample is taken as an example to describe in detail the linguistic features and to illustrate how the linguistic resources serve to express ecological thoughts.

To facilitate the statistical work, different linguistic resources are marked with different symbols. As far as the process types under transitivity are concerned, they are represented in boldface in square brackets (e.g. [material]). Among the six process types, relational processes are further classified into the attributive mode and the identifying mode, which are underlined with double-line (e.g. attributive) and single-line (e.g. identifying) respectively. Concerning the participants of all kinds of processes, they are denoted in parenthesis (e.g. (actor)).

After tagging all the processes in the twenty English eco-hotel profiles, figures obtained are as follows. Altogether, there are 357 processes, involving 186 material processes, 146 relational processes which include 121 attributive relational processes and 25 identifying relational processes, 15 mental processes and 10 existential processes; and no behavioral processes or verbal processes are traced, as is shown in.

TABLE I.

THE DISTRIBUTION OF SIX PROCESS TYPES

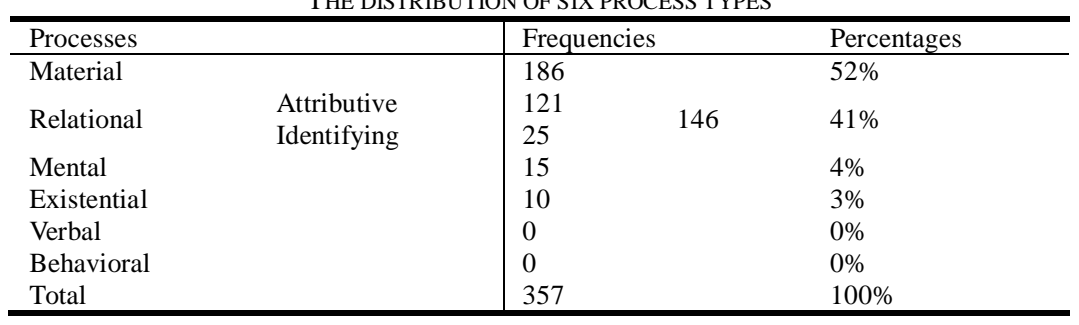

Seen from the table, material processes and relational processes enjoy the overwhelming occurrence in English eco-hotel profiles, taking up 52\% and $41 \%$ respectively. Taking into consideration the nature of eco-hotel profiles, they are a kind of introductory discourses which have the informing, promoting and persuading functions. Similar to other introductory texts, eco-hotel profiles are also designed to introduce and publicize the hotels in terms of the facilities, room arrangements, specialty services, locations, and surrounding environment and landscape. In order to catch potential guests' eyes, the profiles should try utmost to promote the distinctive and outstanding features of the 
eco-hotels concerning the above aspects so as to give consumers an impression that staying in these very hotels will be a unique and unforgettable experience, which may succeed in persuading travelers to come and stay.

The fulfillment of the informing, promoting and thus persuading functions relies largely on the factual and vivid description of the exceptional characteristics of eco-hotels in all possible facets. Since relational processes serve to describe the attributes or determine identities of persons, entities or objects, they are frequently used in the eco-hotel profiles for vigorous description. With regard to relational processes, it is shown in the table that the attributive relational processes noticeably outweigh the identifying relational processes, which manifests that the profiles give priority to describing the attributes, features or qualities rather than ascertaining the identities of the eco-hotels.

What's more, just as the definition of eco-hotel suggests, "eco-hotel is a term used to describe a hotel or accommodation that has made important environmental improvements to its structure in order to minimize its impact on the environment" (http: //en.wikipedia.org/wiki/Eco-hotel), the eco-hotel profiles should foreground their environmental concern and especially the efforts they make to provide guests with comfort and hospitality and meanwhile minimize their impacts on environment. The efforts involve everything they do to furnish guests with fine food, comfortable accommodation, up-scale services, and in the meantime equip guests with ecological and environment-protection consciousness. All these are concerned with processes of "doing", that is, material processes, which thus enjoy striking frequency in these English eco-hotel profiles.

Apart from the two dominant processes, other processes also play important roles in eco-hotel profiles, like mental processes and existential processes, indicated by the statistical findings. Mental processes, known as processes of "sensing", are mainly concerned with feelings, emotions, perception and cognition of human beings. Through the use of mental processes, the profiles enchant the potential guests with the fantastic experience they can feel exclusively in the eco-hotels and thus incite their passion to taste it in person.

Concerning existential processes, they are used in the eco-hotels profiles to inform the prospective guests of something special that exists in the eco-hotels.

\section{B. Sample Analysis}

In this part, one sample is to be analyzed in detail in order to illustrate how the different processes under transitivity help to convey ecological thoughts in English eco-hotel profiles.

\section{Hawaii Island Retreat}

[1] Hawaii Island Retreat at Ahu Pohaku Ho'omaluhia (carrier) is [attributive relational] a sacred site (attribute/ identified) serving [identifying relational] as a physical and spiritual healing retreat center (identifier). [2] They (carrier) are [attributive relational] a luxury eco-conscious spa retreat (attribute/ goal/ carrier) designed [material] to be [attributive relational] in harmony with nature (attribute). [3] Located [attributive relational] along the pristine Kohala coastline with breathtaking views of the ocean (attribute), it (carrier) is [ and groups (actor) may find [material] peace and tranquility (goal) among the ancient stones and healing gardens (attribute). [4] Nestled [attributive relational] among towering Ironwood trees (attribute) their intimate and unique boutique hotel (carrier/ goal) has been constructed [material] with the intention of teaching [material] all who come [material] here how to live [material] in harmony with the earth.

[5] Many of the sustainable practices (goal) they have implemented [material] in their effort to achieve [material] this goal are taught [material] to guests, efforts such as producing [material] their own electricity through solar cells (photovoltaic panels). [6] The retreat (goal/ actor) is designed [material] to use [material] natural lighting during the day and used full-spectrum compact fluorescents for night.

[7] Much of the flooring throughout the retreat (identified) is [identifying relational] Tiger wood, a farmed sustainable hardwood that does not impact [material] native forests (identifier). [8] Their 50 acre Hawaiian sanctuary (carrier) has [attributive relational] abundant organic vegetable gardens and tropical fruit trees (attribute). [9] All organic waste (goal) is recycled [material] back into the soil through an active system of composting. [10] Each individual (actor) that leaves [material] the retreat goes [material] home with a sense of peacefulness and a new understanding that living [material] lightly on the earth (carrier) is [attributive relational] not only an attainable goal (attribute), it (carrier) is [attributive relational] also an achievable reality (attribute).

\section{Description of Linguistics Features}

It is found from the above analysis that only material processes and relational processes are used throughout this text.

These material processes are classified into two groups, according to their participants that include the eco-hotel and guests, so one group is concerned with what the eco-hotel does, and the other is related to what guests may obtain from the experience.

In respect of the eco-hotel, it has made good attempts in the following aspects, a) taking all possible measures to be special and exceptional and meanwhile calling for guests to show respect for and live in harmony with nature, e.g. "Nestled among towering Ironwood trees their intimate and unique boutique hotel has been constructed [material] with the intention of teaching [material] all who come [material] here how to live [material] in harmony with the earth"; b) recommending guests to save natural resources by producing their own electricity so as to guarantee the sustainability of nature, e.g. "Many of the sustainable practices they have implemented [material] in their effort to achieve [material] this goal are taught [material] to guests, efforts such as producing [material] their own electricity through solar cells (photovoltaic panels)"; c) practicing exactly what it preaches, typically reflected by its efforts to save energy and protect 
the environment, which is illustrated by the two examples given. "The retreat is designed [material] to use [material] natural lighting during the day and used full-spectrum compact fluorescents for night"; "All organic waste is recycled [material] back into the soil through an active system of composting".

Several material processes are used to show what the guests may gain from the experience. First, it is revealed that the guests may feel peaceful and tranquil in the eco-hotel, since the hotel is located in such a beautiful natural environment that individuals regard themselves as part of the nature and are inclined to be tamed by nature, e.g. "Located along the pristine Kohala coastline with breathtaking views of the ocean, it is a place where individuals and groups (actor) may find [material] peace and tranquility (goal) among the ancient stones and healing gardens". Furthermore, thanks to the peacefulness and tranquility guests have gained, they come to realize that it is admirable and practical to live without severely affecting nature, e.g. "Each individual (actor) that leaves [material] the retreat goes [material] home with a sense of peacefulness and a new understanding that living [material] lightly on the earth is not only an attainable goal, it is also an achievable reality".

The relational processes, however, are designed for promoting the characteristics and traits of the eco-hotel Hawaii Island Retreat, which are discussed from the following three aspects.

One defines the eco-hotel as a place in which travelers can not only stay away from daily chores and boring work and get relaxed physically, but also feel relieved spiritually because at the eco-hotel they are totally free of tension and pressure which they have to face in daily life. For example, "Hawaii Island Retreat at Ahu Pohaku Ho'omaluhia (carrier) is [attributive relational] a sacred site (attributel identified) serving [identifying relational] as a physical and spiritual healing retreat center (identifier)".

Another elaborates the eco-consciousness of the eco-hotel in that the hotel is nature-oriented and strives for a harmonious relationship with nature, e.g. "They (carrier) are [attributive relational] a luxury eco-conscious spa retreat (attribute/ carrier) designed to be [attributive relational] in harmony with nature (attribute)".

Still another highlights the environment-protection awareness of the eco-hotel, reflected by the raw materials they use for construction. In the example "Much of the flooring throughout the retreat (identified) is [identifying relational] Tiger wood, a farmed sustainable hardwood that does not impact native forests (identifier)", the eco-hotel makes use of renewable natural resources-Tiger wood as flooring material, which exerts no harmful influences on the natural forests or the whole ecological system.

To sum up, the overwhelming use of material processes and relational processes in the sample serves to underline the ecological consciousness and environmental-protection awareness of the eco-hotel Hawaii Island Retreat. The eco-hotel tries all possible means to save energy and maintain sustainability of nature and endeavors to equip guests with the same awareness by resting them in a natural and unspoiled environment, which helps them to realize the intimate relationship between themselves and nature and to free both their body and mind.

\section{Interpretation of Ecological Thoughts}

Based on the above linguistic description, the authors moves on to demonstrate how the language use in English eco-hotel profiles works to embody the ecological thoughts, thus revealing that language not only reflects, but also constructs social-cultural reality.

\subsection{Human Identification with the Nature}

As far as we human beings are concerned, the more we expand "self" to identify with "others" (people, animals, ecosystems), the more we realize ourselves. Thus, one's Self-realization relies on the well being of all the other existences in the ecosystem. Self-realization which is based on interconnectedness and interdependence can direct human to preserve nature actively so as to achieve harmonious co-existence with nature (Lei Yi, 2001, p.45-49).

In the sample, it is emphasized that human should live in harmony with nature, shown by the material processes used in sentence [2] ...eco-conscious spa retreat (attribute/ goal/ carrier) designed [material] to be [attributive relational] in harmony with nature (attribute) and in sentence [4] how to live [material] in harmony with the earth. It is suggested that only when we human beings interact and identify with nature and other existences, can we realize the true meanings of life and gain the simplistic happiness of life, illustrated by the material process used in sentence [3] it (carrier) is [attributive relational] a place where individuals and groups (actor) may find [material] peace and tranquility (goal) among the ancient stones and healing gardens (attribute).

The profile also shows us the efforts made by the hotel in order to maintain a harmonious relationship with nature, which are elaborated by the material process used in sentence [5] ...efforts such as producing [material] their own electricity through solar cells (photovoltaic panels). By producing electricity through solar cells rather than through natural resources, the hotel makes attempts to save natural resources and reduce its negative impacts on nature, thus keeping nature as what it is. What's more, the hotel strives to publicize its nature-friendly consciousness by teaching guests to do the same thing, shown in the material processes used in sentence [4] ...their intimate and unique boutique hotel (carrier/ goal) has been constructed [material] with the intention of teaching [material] all who come [material] here how to live [material] in harmony with the earth and in sentence [5] Many of the sustainable practices (goal) they have implemented [material] in their effort to achieve [material] this goal are taught [material] to guests...

Seen from the above examples, it is realized that only after we human beings identify ourselves and live in harmony with nature can we be blessed with the peaceful and tranquil environment and find the peace and relaxation for our body and mind. Such being the case, we human beings should acknowledge the existence of and acquire a deep-seated 
respect, or even veneration, for all forms of life in the biosphere. More importantly, we should take real actions to guarantee the survival and wellbeing of all kinds of life and the natural environment as well.

\subsection{Simple in Means, Rich in Ends}

Since both human and nature are indispensable and interrelated parts of the intricate web of the ecosystem, we human beings should minimize rather than maximize our influences on nature, remain nature as it is and behave in accordance with law of nature. In the sample, by combining the relational process and material process in sentence [7] Much of the flooring throughout the retreat (identified) is [identifying relational] Tiger wood, a farmed sustainable hardwood that does not impact [material] native forests (identifier), the profile producer attempts to highlight that the eco-hotel is a place where strives not to impact the natural environment. Also, in sentence [10] Each individual (actor) that leaves [material] the retreat goes [material] home with a sense of peacefulness and a new understanding that living [material] lightly on the earth (carrier) is [attributive relational] not only an attainable goal (attribute), it (carrier) is [attributive relational] also an achievable reality (attribute), the combination of relational process and material process reflects that as long as human beings make efforts, it is not only an attainable goal but also an achievable reality for human beings to live lightly or minimize their impacts on nature.

And the relational process used in sentence [1] a sacred site (attribute/ identified) serving [identifying relational] as a physical and spiritual healing retreat center (identifier) serves to show the hotel's efforts in enriching guests' spiritual ethos, instead of merely advertizing material comforts as hotel profiles generally does.

From the above discussion, we get to know that by minimizing human impacts on nature, we can harvest a friendly living environment and a harmonious relationship with nature which assures us everlasting prosperity and welfare. This is a lifestyle which deep ecologists suggest individuals to pursue, "simple in means, rich in ends" (Devall \& Sessions, 1985, p.68). Life quality mentioned here actually underlines the spiritual life, which implicates love, happiness, security and access to nature and other basic emotional needs.

To conclude, through the use of different transitivity processes, especially material processes and relational processes, the eco-hotel profile conveys the above-mentioned ecological thoughts and environmental concern.

\section{Explanation of the Social Contexts}

After having discussed about the ecological thoughts represented by the language use in eco-hotel profiles, we go further to explore the social contexts in which profit-oriented businessmen tend to express their environmental concern in the eco-hotel profiles.

As mentioned above, the depletion of natural resources triggers wars and combat among countries for oil, petrol and maybe water in the near future. The pollution of air and water undermines human health as well as longevity. Global warming arising from the excessive emission of carbon dioxide brings about the rising of sea level and climatic anomaly. The ecological crises are stemming from the stance that human beings' benefits and interests should come before nature's wellbeing. It is not unusual for human to sacrifice the ecological environment and natural resources for material wealth or comfort, which is justified by the human-centered instrumentalism that regards nature simply as tools. What is worse, the instrumentalism results in the rejection and conquest of nature by human beings, which eventually brings about the dissimilation and alienation between man and nature and between man and man. And human beings have gradually lost mutual-trust, responsibilities, morality and the noble quality of appreciating differences, diversity and richness. All these are detrimental to the sustainable development of human society. As a result, to remove the ecological crises which have grown in frequency and severity, a change from human-centered viewpoints into eco-centric values is a must and should be fulfilled as soon as possible.

Under such contexts, it is wise for businessmen to embody their ecological thoughts in eco-hotel profiles. By doing so, for one thing, they raise people's awareness of the significance of nature and environment to human beings; and for another, they earn themselves fame and reputation for their environmental ethics. This serves to bring continuous guests to the hotels, which is the ultimate purpose of the hotel profiles. With both fame and fortune gained, it is needless to say that businessmen are voluntary to express their ecological thoughts in the eco-hotel profiles and in the meanwhile try utmost to guarantee a natural environment for simple, ecology-oriented and sustainable tourism.

\section{CONCLUSION}

In modern society, the environmental pollution and ecological crises are so severe and rampant that they have cast detrimental effects on human lives in all possible respects. Men of insight become alert to the phenomenon and try hard to raise the ecological consciousness of the public by various means, such as "green" speeches delivered by statesmen, environment-protection actions taken by individuals, etc. This study, however, is designed to probe into the ecological consciousness encoded in English eco-hotel profiles. Theoretical foundations are discussed thoroughly, and an analytical frame is proposed based on Fairclough's three-dimensional model. In accordance with the proposed frame, the author makes a detailed analysis of the English eco-hotel profiles in three steps as follows, description of linguistic features in English eco-hotel profile texts in terms of transitivity, interpretation of ecological thoughts revealed by the linguistic resources and explanation of social reasons.

\section{A. Major Findings}

After the analysis, the following major findings are obtained. 
First, the English eco-hotel profiles make use of various linguistic resources, among which, material processes and relational processes under transitivity are most frequently used. Material processes are mainly used to inform potential consumers of the nature-oriented efforts and actions the eco-hotels have taken; relational processes are largely employed to promote and highlight the unique natural environment where eco-hotels are located and the spiritual enjoyment brought to the guests by history and culture. All these linguistic resources work together to persuade the prospective customers into paying a visit to the eco-hotels for a unique and ecology-friendly experience.

Second, all the linguistic resources used in English eco-hotel profiles help to express certain kinds of ecological thoughts. It is learned that human beings should identify ourselves with nature and view ourselves as part of nature so as to live in harmony with nature and find the true meanings of life; owing to the interconnectedness and interdependence between human and nature, we mankind should minimize rather than maximize our impacts on nature and seek after a lifestyle that is "simple in means, rich in ends" so as to maintain the prosperity of natural universe and the sustainable development of human society.

Third, in a society replete with ecological crises and irrational people who chase only the material comfort, those are urgently needed who speak for nature and propagate nature-friendly lifestyle. Eco-hotel founders, therefore, may gain both fame and fortune, thanks to the ecological thoughts they express through the language use in their eco-hotel profiles. Thus, they, as profit-seeking businessmen, are voluntary to express and disseminate ecological thoughts or consciousness.

It is also discovered that the language use helps to convey ecological thoughts or ideologies, which may in turn influence or manipulate readers' ecological ideologies by changing their "human-centered" values into "eco-centric" world view. Thus, individuals should be more critical in the language use that expresses ecological or un-ecological elements.

And the study has some implications for the introductory discourses, like eco-hotel profiles. It is advisable for introductory discourses to select linguistic resources elaborately in the expression of particular ideologies or viewpoints so as to exert profound effects on the potential readers, which may help to achieve the ultimate purposes of the introductory discourses. For instance, the use of particular linguistic resources may talk prospective consumers into purchasing certain products by impressing them with a certain consumption pattern, or persuade job applicants into working for a company by arresting them with the special corporate culture of the company.

\section{B. Limitations}

The present study has its limitations.

First, regarding the analysis of linguistic features, we only analyze transitivity but put aside nominalization, voice, etc. A comprehensive study of all these linguistic devices may turn out more valid.

Second, the eco-hotel profiles collected are written in English, so the conclusions thus reached simply reflect the discursive and linguistic practices of the English language.

Third, ecological study is so extensive because ecologists have absorbed in its theory the latest achievements of all kinds of natural science and a wide range of humanistic thoughts. Thus, the exploration of ecological thoughts is not all-inclusive in the study.

Last but not least, in the study, only the distribution of linguistic resources that reflect ecological thoughts is examined. A comparison between the frequency of ecological linguistic resources and that of non-ecological linguistic resources will make the conclusion thus reached more reliable and soundly based.

Accordingly, further studies are suggested to conduct from the aspects in which the present study is not involved. Studies can be carried out to probe into ecological thoughts through analysis of such linguistic devices as nominalization and voice, etc. It is also worth trying to make a comparison between different languages, say, English and Chinese, to see how the language use of two languages differs when employed to express ecological thoughts and try to seek reasons from a cross-cultural perspective.

\section{REFERENCES}

[1] Devall, B. \& Sessions, G. (1985). Deep Ecology: Living as if Nature Mattered. Salt Like City: Peregrine Smith Books.

[2] Fairclough, N. (1989). Language and Power. London and New York: Longman.

[3] Fairclough, N. (1992). Discourse and Social Change. Cambridge: Polity Press.

[4] Fairclough, N. (1995). Critical Discourse Analysis: The Critical Study of Language. London and New York: Longman.

[5] Halliday, M. A. K. (1985/1994). An Introduction to Functional Grammar. London: Edward Arnold.

[6] Huang Guowen. (2001). Theory and Practice of Discourse Analysis. Shanghai: Foreign Language Teaching Press.

[7] Lei Yi. (2001). Study of Deep Ecological Thoughts. Beijing: Tsinghua University Press.

[8] Thompson, G. (1996) Introducing Functional Grammar. Beijing: Foreign Language Teaching and Research Press and London: Edward Arnold.

[9] http://en.wikipedia.org/wiki/Eco-hotel (accessed 21/9/2010).

[10] http://www. Ecohotelsoftheworld.com (accessed 30/8/2010).

[11] http://www.ecohotelsoftheworld.com/adrere-amellal-5.html (accessed 30/8/2010).

[12] http://www.ecohotelsoftheworld.com/arenas-del-mar-4.html (accessed 30/8/2010).

[13] http://www.ecohotelsoftheworld.com/balamku.html (accessed 30/8/2010).

[14] http://www.ecohotelsoftheworld.com/bushy-point-fernbirds-4.html (accessed 30/8/2010). 
[15] http://www.ecohotelsoftheworld.com/dar-itrane-ecolodge-4.html (accessed 30/8/2010).

[16] http://www.ecohotelsoftheworld.com/greenspace-4.html (accessed 30/8/2010).

[17] http://www.ecohotelsoftheworld.com/hawaii-island-retreat-3.html (accessed 30/8/2010).

[18] http://www.ecohotelsoftheworld.com/pousada-picinguaba-4.html (accessed 30/8/2010).

[19] http://www.ecohotelsoftheworld.com/rosalie-forest-eco-lodge-2.html (accessed 30/8/2010).

[20] http://www.ecohotelsoftheworld.com/saadani-safari-lodge-2.html (accessed 30/8/2010).

[21] http://www.ecohotelsoftheworld.com/seaport-hotel.html (accessed 30/8/2010).

[22] http://www.ecohotelsoftheworld.com/the-atami-hotel.html (accessed 30/8/2010).

[23] http://www.ecohotelsoftheworld.com/the-harmony-hotel-4.html (accessed 30/8/2010).

[24] http://www.ecohotelsoftheworld.com/timarai-bamboo-resort-3.html (accessed 30/8/2010).

[25] http://www.ecohotelsoftheworld.com/udayana-eco-lodge-2.html (accessed 30/8/2010).

[26] http://www.ecohotelsoftheworld.com/villa-magnolia-3.html.

[27] http://www.ecohotelsoftheworld.com/whitepod-2.html (accessed 30/8/2010).

[28] http://www.ecohotelsoftheworld.com/wilderness-lodge-arthur-s-pass-5.html (accessed 30/8/2010).

[29] http://www.ecohotelsoftheworld.com/yangshuo-mountain-retreat-3.html (accessed 30/8/2010).

[30] http://www.ecohotelsoftheworld.com/yangshuo-village-inn-3.html (accessed 30/8/2010).

Juan Qiu has got an M.A. in Foreign Language and Literature majoring in Business English Studies from Guangdong University of Foreign Studies, Guangzhou, China, in 2011 and received her B.A. majoring in English from Tianjin University of Commerce, Tianjin, China, in 2009. She is currently an instructor in the School of Foreign Languages, Wuhan Polytechnic University, Wuhan, China. Her primary research interests include eco-critical studies, discourse analysis, intercultural communication and business English studies. 